Zhou, K.; Stüber, J.; Schubert, R.-L.; Kabbe, C.; Barjenbruch, M.

\title{
Full-scale performance of selected starch- based biodegradable polymers in sludge dewatering and recommendation for applications
}

Journal article | Accepted manuscript (Postprint)

This version is available at https://doi.org/10.14279/depositonce-8171

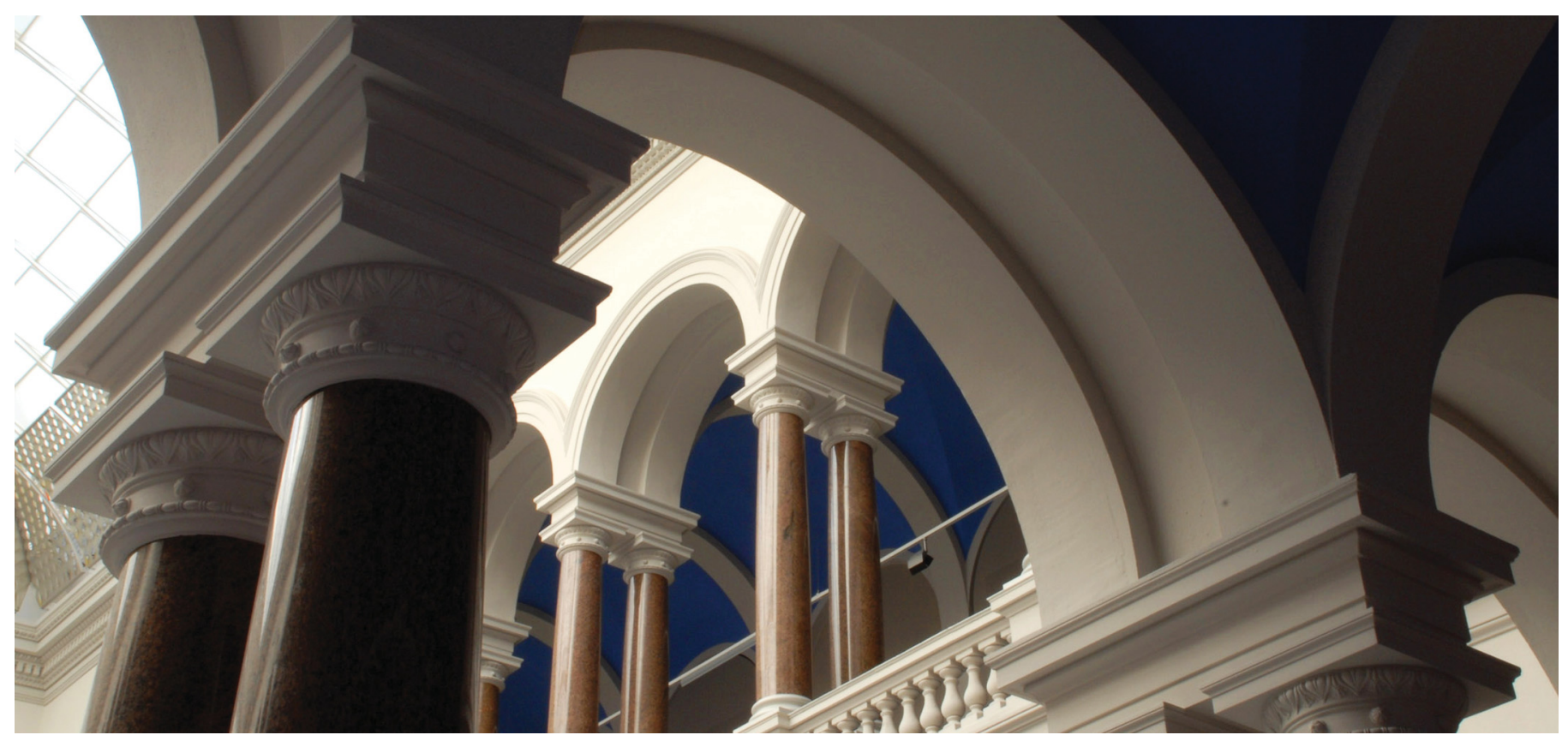

Zhou, K., Stüber, J., Schubert, R.-L., Kabbe, C., \& Barjenbruch, M. (2017). Full-scale performance of selected starch-based biodegradable polymers in sludge dewatering and recommendation for applications. Water Science and Technology, 77(1), 7-16.

https://doi.org/10.2166/wst.2017.476

(C)IWA Publishing 2017. The definitive peer-reviewed and edited version of this article is published in Water Science \& Technology 77(1), 7-16, 2017, 10.2166/wst.2017.476 and is available at www.iwapublishing.com. 


\title{
Full-scale performance of selected starch-based biodegradable polymers in sludge dewatering and recommendation for applications
}

\author{
Kuangxin Zhou, Johan Stüber, Rabea-Luisa Schubert, Christian Kabbe \\ and Matthias Barjenbruch
}

\begin{abstract}
$\overline{\text { ABSTRACT }}$
Agricultural reuse of dewatered sludge is a valid route for sludge valorization for small and mid-size wastewater treatment plants (WWTPS) due to the direct utilization of nutrients. A more stringent of German fertilizer ordinance requires the degradation of $20 \%$ of the synthetic additives like polymeric substance within two years, which came into force on 1 January 2017. This study assessed the use of starch-based polymers for full-scale dewatering of municipal sewage sludge. The laboratory-scale and pilot-scale trials paved the way for full-scale trials at three WWTPs in Germany. The general feasibility of applying starch-based 'green' polymers in full-scale centrifugation was demonstrated. Depending on the sludge type and the process used, the substitution potential was up to $70 \%$. Substitution of $20-30 \%$ of the polyacrylamide (PAM)-based polymer was shown to achieve similar total solids (TS) of the dewatered sludge. Optimization of operational parameters as well as machinery set up in WWTPs is recommended in order to improve the shear stability force of sludge flocs and to achieve higher substitution potential. This study suggests that starch-based biodegradable polymers have great potential as alternatives to synthetic polymers in sludge dewatering.

Key words | shear stability, sludge dewaterability, starch-based polymer
\end{abstract}

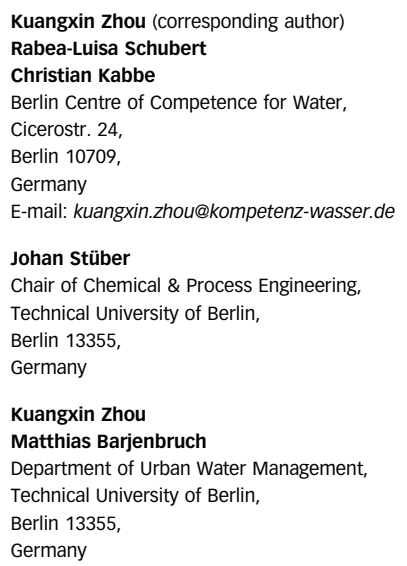

\section{HIGHLIGHTS}

- A jar-testing methodology was developed for the assessment of the optimal polymer dose for sewage sludge.

- The dewaterability of starch-based polymers and polyacrylamide (PAM) synthetic polymers were compared in pilot-scale and full-scale tests.

- The substitution potential of synthetic polymers in wastewater treatment plants (WWTPs) was evaluated.

- Recommendations for the future application of starchbased polymers were given.

\section{INTRODUCTION}

Agricultural reuse of dewatered sludge is a valid route for sludge valorization for small and mid-size WWTP due to the direct utilization of nutrients. As shown in Figure 1, about $51 \%$ of the sewage sludge generated in the 28 European countries (including the UK and Switzerland) was applied directly in agriculture. About 23.7\% (428,000 dry tonnes) of the accumulated sludge in Germany was valorized in agriculture in 2015 (Destatis 2016). However, synthetic flocculants based on PAM may have a negative impact on the environment due to toxicity and nonbiodegradability (Khachan et al. 20II). A more stringent German fertilizer ordinance (DüMV 20I2) for this valorization route requires the degradation of $20 \%$ of the polymeric substance within two years from the year 2017, so as to increase the soil's water-holding capacity. Regarding the amendment of German fertilizer ordinance (BMEL 20I6) from 1 January 2019, the quantity of applied synthetic polymers in agriculture land must not exceed $45 \mathrm{~kg}$ active substance (AS) per hectare within three years. Regardless of the long-term strategic decision about sludge valorization and phosphorus recycling, the partial or total 


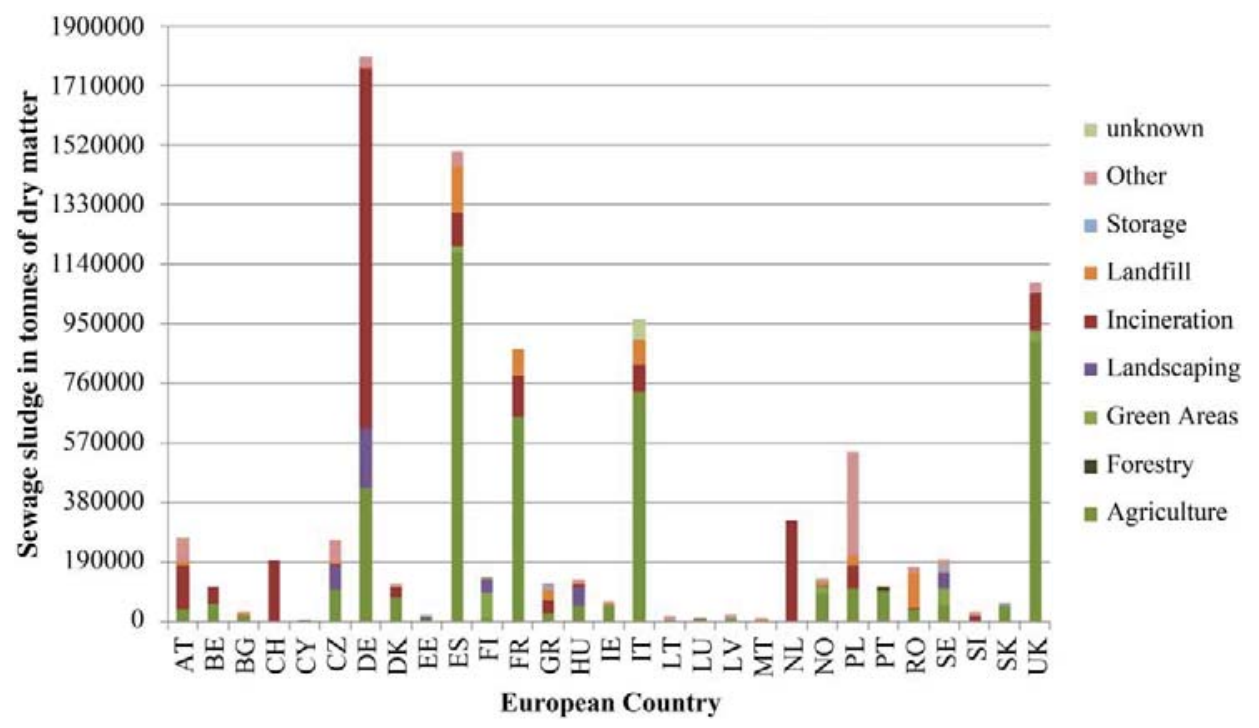

Figure 1 Disposal and recycling routes for sewage sludge in European countries (BAFU 2013; Destatis 2016; EurEau 2016; Eurostat 2016) $(A T=A u s t r i a, ~ B E=B e l g i u m, ~ B G=B u l g a r i a, ~ C H=$ Switzerland, $\mathrm{CY}=$ Cyprus, $\mathrm{CZ}=$ Czech Republic, $\mathrm{DE}=$ Germany, $\mathrm{DK}=$ Denmark, $\mathrm{EE}=$ Estonia, $\mathrm{ES}=\mathrm{Spain}, \mathrm{FI}=$ Finland, $\mathrm{FR}=\mathrm{France}, \mathrm{GR}=\mathrm{Greece}, \mathrm{HU}=\mathrm{Hungary}, \mathrm{IE}=\mathrm{Ireland}, \mathrm{IT}=$ Italy, LT = Lithuania, LU = Luxembourg, LV = Latvia, $\mathrm{MT}=$ Malta, $\mathrm{NL}=$ Netherlands, $\mathrm{NO}=$ Norway, $\mathrm{PL}=$ Poland, $\mathrm{PT}=\mathrm{Portugal}, \mathrm{RO}=\mathrm{Romania}, \mathrm{SE} S \mathrm{Sweden}, \mathrm{SI}=\mathrm{Slovenia}, \mathrm{SK}=\mathrm{Slo}-$ vakia, UK = United Kingdom).

substitution of PAM-based polymers with biodegradable polymers is therefore an environmentally friendly alternative.

PAM-based polymers significantly improve dewatering results and therefore less energy is required for transport. However, the increasing use of non-biodegradable polymers may cause serious environmental problems (Lu et al. 2009). This reminds us to focus on natural, renewable polymers (Scott 2000), e.g. starch, chitosan, which are inherently biodegradable (Chiellini \& Solaro I996) and can be considered to be promising candidates for meeting different requirements. Starch is mainly composed of two homopolymers of D-glucose (Pareta \& Edirisinghe 2006), which form nontoxic residues after degradation. Starch-based completely biodegradable polymers (SCBP) combine the individual advantages of starch and synthetic polymers, providing promising potential for sludge dewatering.

This study assesses the use of starch-based polymers for full-scale dewatering of municipal wastewater sludge. The laboratory-scale and pilot-scale trials paved the way for full-scale trials. Varying blends of starch-based polymer and PAM-based polymer were tested in laboratory-scale trials with jar tests and drop-off tests. Pilot-scale trials with a centrifuge identified the optimization and quantification of dewatering results. Short-term trials on a full-scale centrifuge, drum filter and belt thickener at three WWTPs in Germany with the blends demonstrated the substitution potential with different dewatering devices and showed the limits of the state-of-the-art product.

\section{MATERIALS AND METHODS}

\section{Study sites and sampling locations}

Laboratory-scale trials were conducted on the premises of WWTP Schönebeck and WWTP Putzhagen (Gütersloh) whereas pilot- and full-scale trials took place at WWTP Steinhof (Braunschweig), WWTP Schönebeck and WWTP Putzhagen. Since the sludge properties and types varied significantly from one WWTP to another, the starch-based polymers were tested with three sludge types collected from the different WWTPs. Table 1 summarizes the sludge types and characteristics. WWTP Steinhof is one of the very few large-scale agricultural reuse sites in Germany. Sludge from WWTP Schönebeck and Putzhagen is also used in agriculture after anaerobic digestion.

\section{Polymers}

The polymers selected for use in this study are listed in Table 2. Two starch-based polymers, Hydrex ${ }^{\mathrm{TM}} \mathrm{H} 0661$ and H6864 (new products not yet on the market), are extracted from non-genetically modified potatoes, and were provided 
Table 1 | Tested sludge types and characteristics

\begin{tabular}{|c|c|c|c|c|c|}
\hline WWTP & Sludge type & Dewatering/thickening & Applied processes & Total solids in \% & WWTP population equivalent \\
\hline Schönebeck & Excess sludge & Drum filter & Bio-P & 0.74 & 32,000 \\
\hline Steinhof & Digested excess sludge & Centrifuge & Bio-P; struvite precipitation & $2.8-3.5$ & 350,000 \\
\hline Putzhagen & Excess sludge & Belt thickener & Chemical P-removal & $0.6-0.8$ & 150,000 \\
\hline
\end{tabular}

Table 2 | List of tested polymers

\begin{tabular}{lllll} 
Product & $\begin{array}{l}\text { Molecular } \\
\text { weight }\end{array}$ & charge & $\begin{array}{l}\text { charge } \\
\text { density }\end{array}$ & origin \\
\hline Hydrex $^{\mathrm{TM}}$ H0661 & High & Positive & n.a. & Starch \\
$\begin{array}{l}\text { Hydrex } \\
\text { EM H6864 }\end{array}$ & High & Positive & High & Starch \\
$\begin{array}{c}\text { Eurofloc K7CZST } \\
\text { (Schönebeck) }\end{array}$ & High & Positive & Medium & PAM \\
$\begin{array}{c}\text { POLY SEPAR } \\
\text { PK1440 (Steinhof) }\end{array}$ & High & Positive & n.a. & PAM \\
$\begin{array}{c}\text { Reiflock RF1204 A } \\
\text { (Putzhagen) }\end{array}$ & High & Positive & Very high & PAM \\
\hline
\end{tabular}

n.a., not available.

by Veolia Water STI. Three PAM-based polymers used for the respective WWTPs were tested as references. Blends of starch-based and PAM-based polymers were tested in order to identify the case-specific substitution potential. The substitution potential is calculated with respect to the amount of the synthetic polymer replaced, bearing in mind the optimal polymer dose (OPD). The substitution potential is given as the amount replaced in $\mathrm{kgAS} /$ megagram $(\mathrm{Mg})$ total solids (TS) (kgAS/MgTS) as well as in \%.

PAM-based polymers should be made up according to best-practice advice and the recommendations of the polymer manufacturer. They should be allowed to mature for at least 45 minutes and be consumed within 4 hours (DWA-M-366 2013).

The H6864 and H0661 do not need any maturation time, but complete mixing should be ensured. During the pilot- and full-scale trials a mixing time of 15 minutes was sufficient using an impeller mixer.

\section{Jar testing to determine OPD}

In this study a jar-testing titrimetric method was developed in order to determine the OPD. The reliability and validity of this method has been repeatedly confirmed by testing the original polymer demand in different WWTPs. The jar test was performed using two starch-based polymers and the combination of PAM-based polymers. The equipment used was a laboratory flocculator; solutions were observed in four parallel jars. The procedure of the jar test was as follows: for each jar test $200 \mathrm{~mL}$ of sludge was added to a $500 \mathrm{~mL}$ beaker and the predetermined polymer solution, approximately $60 \%$ of the total hypothetical demand, was added. The mixed liquor was first stirred for $2 \mathrm{~min}$ at a speed of 200 rotations per minute (rpm), then for another $5 \mathrm{~min}$ at a speed of $30 \mathrm{rpm}$. The polymer demand was observed through the change in floc size; see Figure 2 for an example using digested sludge from WWTP Stahnsdorf in Germany. If required, $2 \mathrm{ml}$ more polymer was added, approximately $1 \mathrm{kgAS} / \mathrm{MgTS}$, until the larger floccules appeared and reached the optimum polymer dose. The polymer solutions were made up with tap water as in the fullscale plant, and all experiments were performed at ambient temperature $\left(18-23^{\circ} \mathrm{C}\right)$. For all trials the planned blend, e.g. $50: 50 \%$ of the synthetic and starch-based polymers, were prepared in mixed solution and dosed together.

\section{Drip-off tests}

In order to determine the achievable TS and filterability of the sludge, the drip-off test was performed. For the drip-off test $200 \mathrm{ml}$ sludge were dosed with the optimum polymer demand and mixed at $200 \mathrm{rpm}$ for 15 seconds. Then it was filtered through a micro sieve with a pore size of $100 \mu \mathrm{m}$. The accumulated permeate volume was documented every 5-10 seconds until the volume in the graduated cylinder was stable.

\section{Pilot-scale test}

Pilot-scale trials were conducted with the polymer HYDREX H6864 in cooperation with Institute of Sanitary and Environmental Engineering Braunschweig (ISWW). The pilot-scale centrifuge Hiller DP15-422 with a maximal capacity of 400 1/hour was used for two sludge types: mesophilic digested excess sludge and digested mixed sludge (a mixture of thermophilic digested primary, mesophilic digested excess sludge and thermophilic digested cosubstrate). Sludges were tested with different polymer 

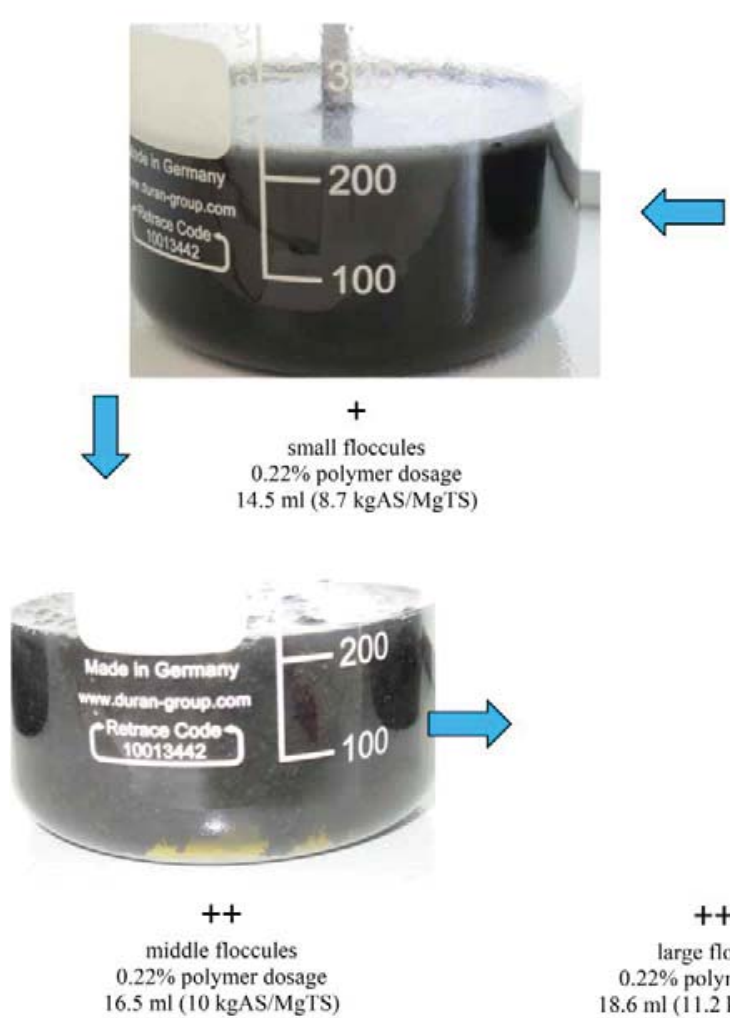

Figure 2 | Sludge floccules with different polymer doses.

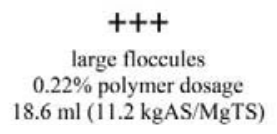

$0.22 \%$ polymer dosage
$18.6 \mathrm{ml}(11.2 \mathrm{kgAS} / \mathrm{MgTS})$

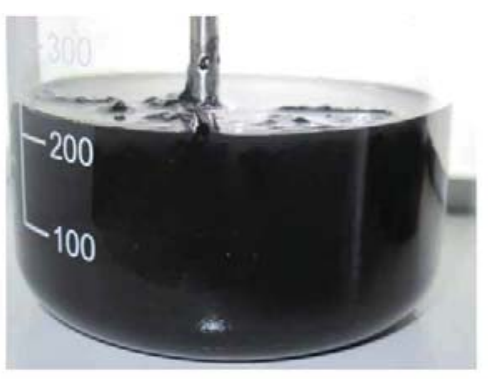

no flocculation

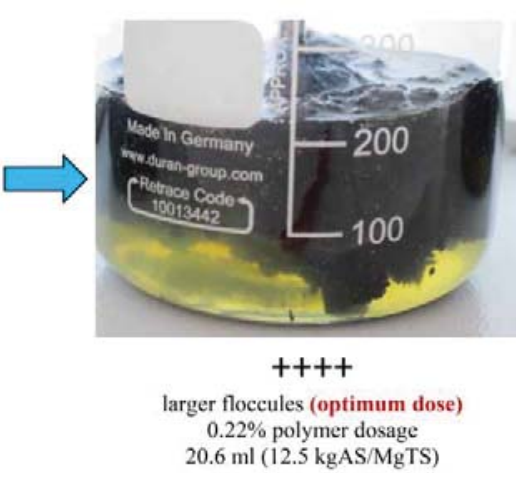

blends and compared to PAM-based polymers. Both polymers were made with a concentration of 0.2 mass $\%$. In order to confirm the correct concentration, the TS of the polymer solutions was measured for each sample.

The separation ratio was evaluated through the total suspended solids (TSS) of the feed, dewatered sludge and centrate, which is defined as:

\section{Separation ratio}

$$
=\frac{\left(\mathbf{T S S}_{\text {feed }}-\mathbf{T S S}_{\text {centrate }}\right) \times \mathbf{T S S}_{\text {dewatered sludge }}}{\left(\mathbf{T S S}_{\text {dewatered sludge }}-\mathbf{T S S}_{\text {centrate }}\right) \times \mathbf{T S S}_{\text {feed }}} \times 100[\%]
$$

\section{Full-scale test}

At WWTP Steinhof digested mixed sludge was centrifuged by a Flottweg Dekanter Z53 with addition of the synthetic polymer PK1440 and the starch-based polymer H6864. The centrifuge was started and torque, differential speed and polymer dose was adapted in order to achieve a minimum separation ratio of $90 \%$ and highest possible TS of the dewatered sludge. The sludge flow was kept constant at $20 \mathrm{~m}^{3}$ /hour and the TS value of sludge to be dewatered was between $2.8-3.1 \%$. TS, loss on ignition (LOI) and TSS measurements were carried out on site as well as at the laboratory of WWTP Steinhof. The pipeline afterwards was approximately $15 \mathrm{~m}$ long, thus a contact time of $45-55$ seconds for the H6864 was achieved. The centrifuge was operated over night with the synthetic polymer PK1440 and after a stable operation was achieved the reference sample was taken in the morning. The starch-based polymer was added in increments of $10 \%$ over the next hours, reducing the synthetic polymer mass ratio from $70 \%$ to $50 \%$.

At WWTP Schönebeck a drum filter is used for thickening. The starch-based polymer H6864 was tested with sludge $17 \mathrm{~m}^{3}$ /hour with an average polymer demand of approximately $4.5 \mathrm{~kg}$ AS/MgTS. The synthetic and the starchbased polymers were mixed once the synthetic polymer was saturated. A blend with $0.1 \%$ AS was prepared. The blend was dosed into the sludge stream just before the flocculation tank. After flocculation, the sludge mixture passed to the drum filter where a stainless steel sieve is used for separation. The mesh size was $400 \mu \mathrm{m}$.

Full-scale trials were also performed at WWTP Gütersloh for two days. The excess sludge was treated with a belt thickener Bellmer Turbodrain, Compact TDC 08, with a sieve 
diameter of $0.7 \mathrm{~mm}$. Excess sludge entered the process with $0.6-0.8 \%$ TS at a sludge flow of $27 \mathrm{~m}^{3} /$ hour. Retention time on the belt was approximately $2 \mathrm{~min}$, and the thickened sludge contained $4-6 \% \mathrm{TS}$. In the continuous process the positively charged polymer (Reiflock RF1204A, 48\% TS) and starch-based polymer $\mathrm{H} 0661$ were dosed at a flow of $1 \mathrm{~m}^{3}$ / hour, with an $0.1 \%$ dilution (polymer solution), meaning $0.048 \%$ AS and $2.7 \mathrm{~kg}$ AS/MgTS.

\section{RESULTS AND DISCUSSION}

\section{Laboratory-scale trials}

The laboratory-scale study was performed to investigate the efficiency of different starch-based biodegradable polymers. As an example the jar-test results for excess sludge at WWTP Putzhagen are presented in the following sections.

Figure 3 shows the results of the tests run with excess sludge from WWTP Putzhagen. Application of starchbased polymer H6864 and H0661 increased the optimal total polymer demand from 5.5 to $8.5 \mathrm{kgAS} / \mathrm{MgTS}$. The increased OPD is an undesirable effect and diminishes the positive impact of starch-based polymer application. The operating costs will rise even considering an optimistic price for starch-based polymers in the same range as the synthetic polymers. Substitution of approximately $40 \%$ of the PAM-based polymers appears technically feasible when applying a blend of 50\% starch-based polymer. H6864 and
H0661 has the same performance as OPD, The shear force stability can be assessed with the drip-off test.

Figure 4 shows the results of drip-off test with different blends of starch and PAM-based polymers. The obvious lower volume for the samples treated with blends can be explained by smaller and/or weaker flocs formed by the starch-based polymer. The flocs break during mixing and transfer to the filtration unit. The small flocs block the $100 \mu \mathrm{m}$ sieve and clogging prevents proper filtration. H0661 shows a better performance with higher filtration volume than H6864. For this reason H0661 was chosen for further full-scale investigations.

In general, testing different sludges with varying blends of PAM-based and starch-based polymers gave a broad overview of the feasibility and applicability of starch-based polymers. Applying a blend of starch-based and PAM-based polymers can increase the total polymer demand and therefore the substitution potential has to be calculated accordingly. The flocs showed lower shear force stability and are therefore less suitable for process steps requiring strong flocs, e.g. dewatering with centrifuges. In order to introduce a starch-based polymer as an alternative or a partial substitute for PAM-based polymers, the applicability in full-scale processes has to be proven.

\section{Pilot-scale trials}

The pilot-scale centrifuge can be used to predict the full-scale dewatering results. Different dosing and mixing conditions were tested during the pilot-scale trials, and the best

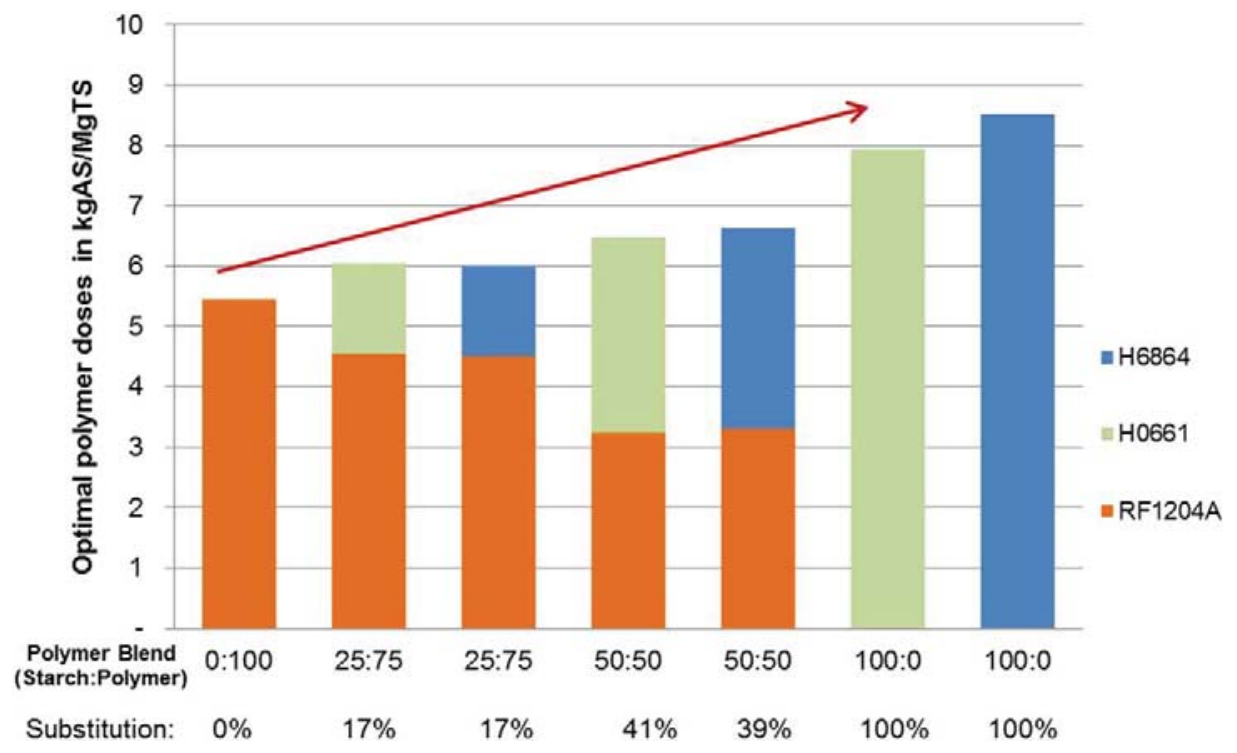

Figure 3 | Jar-test results with different blends of starch-based polymer and original polymer at WWTP Putzhagen. 


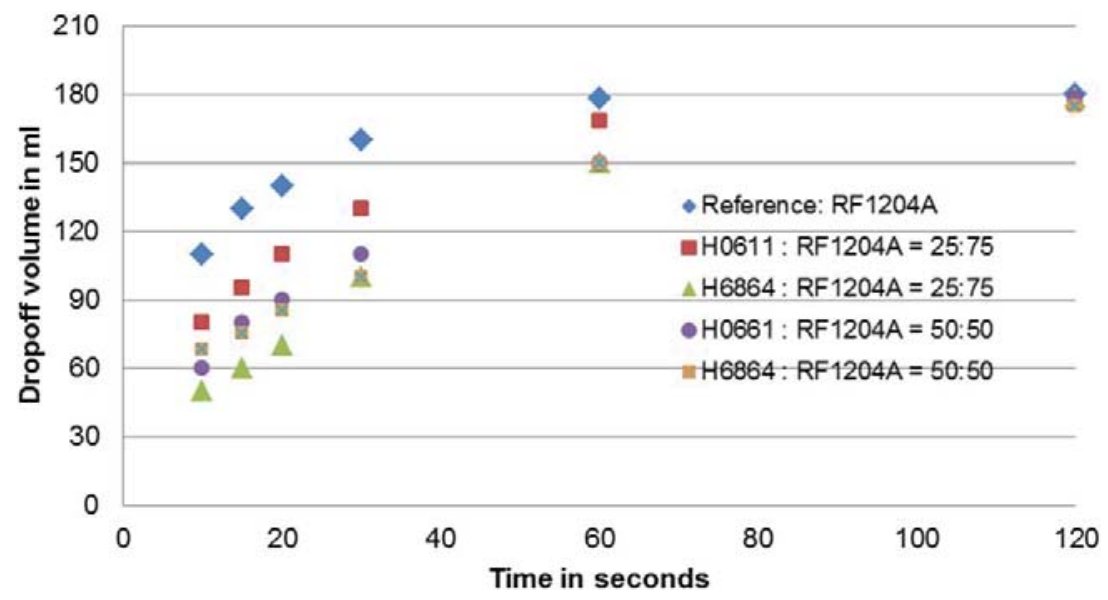

Figure 4 | Results of drip-off test at WWTP Putzhagen.

identified setup was dosing the starch-based polymer H6864 prior to the PAM-based polymer PK1440. The H6864 has a positive charge that allows for surface particle neutralization resulting in flocculation. PAM-based PK1440 has the ability to bring together particles suspended in solution by an adsorption process. For each trial run the differential speed as well as the total polymer dose was adapted by balancing the TS of the dewatered sludge and the quality of the centrate, thus the separation ratio. The bowl speed was kept at $6,000 \mathrm{rpm}$, except for the one trial run using 100\% $\mathrm{H} 6864$. Due to the insufficient results with the starch-based polymer alone, a bowl speed of 3,400 rpm was used. Besides this anomalous trial run, the differential speed was kept between 1.4-2 rpm to achieve a high torque, thus increasing the TS of the dewatered sludge. For the trial run with 100\% H6864 the differential speed was set at $5 \mathrm{rpm}$. Table 3 summarizes the operational parameters for the pilot-scale centrifuge and gives the sludge characteristics throughout the trials.

The results of total polymer dose, TS dewatered sludge, substitution and separation ratio of digested excess sludge are shown in Figure 5. The bars indicate the total polymer dose and the triangles specify the achieved TS of the dewatered sludge. For each trial run the blend and the achieved substitution with regards to the reference is shown and the fraction of PAM-based and starch-based polymer are highlighted. The achieved TS of the dewatered sludge for all blends lay within a narrow range $(+/-0.7 \%)$ and were similar to the TS achieved with the PAM-based polymer. Additionally, the total polymer dose only increased significantly for the blend consisting of 70\% H6864. But even with this higher total polymer dose a substitution of $64 \%$ of the PAM-based polymer was possible, achieving the same TS for the dewatered sludge. The separation ratio was above 99\%, indicating an optimized operation.

The limitation is demonstrated by applying $100 \%$ H6864. The total polymer increased and at the same time the TS of the dewatered sludge and the separation ratio decreased below an acceptable value. This confirms the outcomes of the jar tests. The flocs formed by the starch-based polymer alone do not develop a sufficient shear force

Table 3 | Characteristics of digested excess sludge at WWTP Steinhof for pilot trials and operation of pilot-scale centrifuge

\begin{tabular}{llll}
\hline Digested excess sludge & & & \\
TS & LOI & $\mathrm{pH}$ & Temperature \\
$\%$ & $\%$ of TS & & ${ }^{\circ} \mathrm{C}$ \\
$3.0-3.4$ & $63.5-69.4$ & $6.6-8.7$ & $32.5-36$ \\
Pilot centrifuge operation data & & \\
Bowl speed & Rotational speed & Torque & Sludge throughput \\
rpm & rpm & $\%$ & $1 /$ hour \\
$\sim 6,000$ & $1.4-2.0$ & $22-33$ & $280-300$ \\
\hline
\end{tabular}




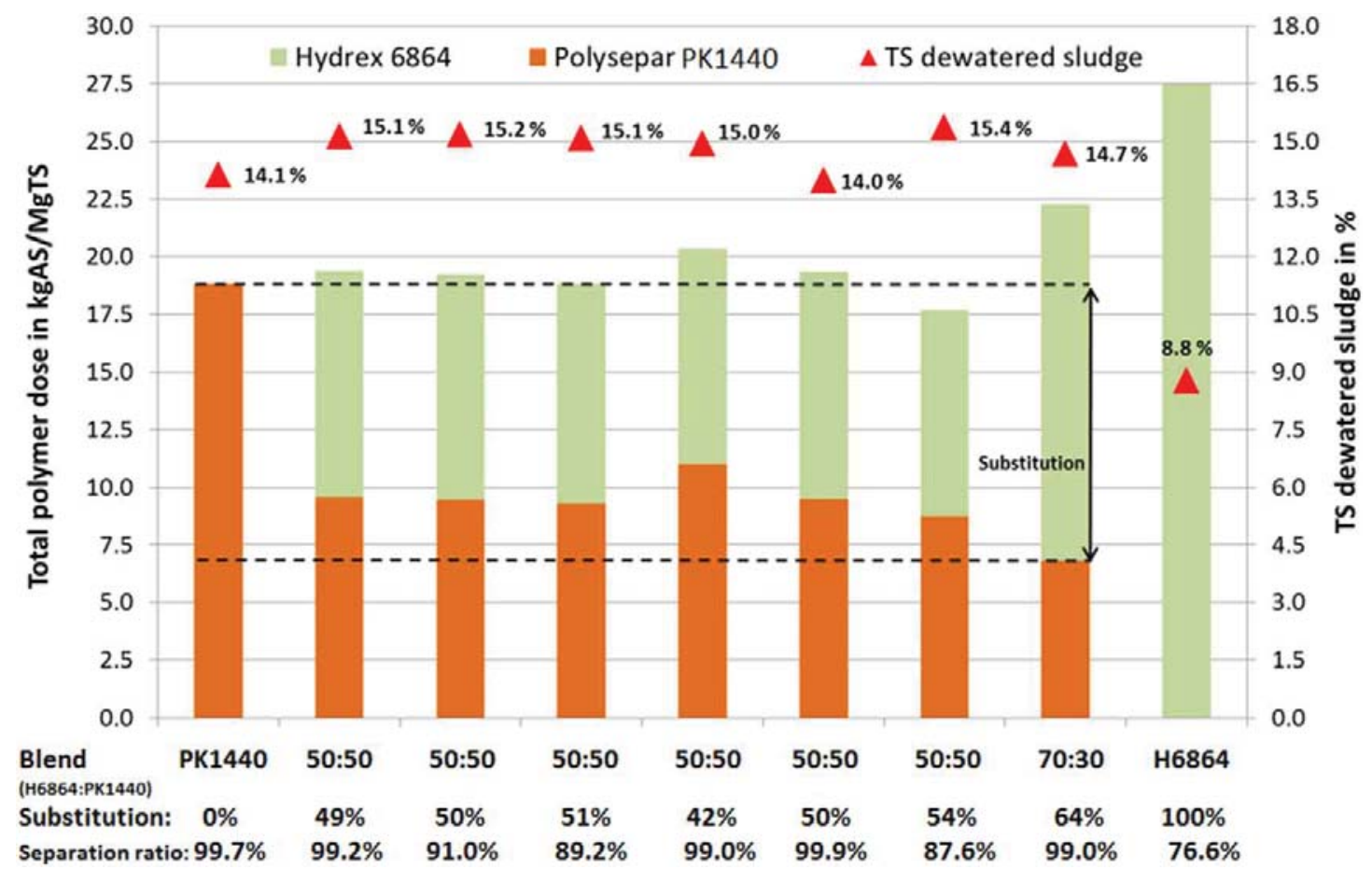

Figure 5 | Results of pilot-scale trials digested excess sludge.

stability required for centrifugation. Therefore, full-scale trials targeting a substitution of up to $50 \%$ of the PAMbased polymer was conducted at WWTP Steinhof.

\section{Full-scale trials}

\section{Full-scale trials at WWTP Steinhof with centrifuge}

Full-scale trials were first conducted at WWTP Steinhof to prove the feasibility of the starch-based polymer H6864 in centrifugation process. Table 4 shows the different operation parameters of the digested mixed sludge and centrifuge. Due to the experience gained with the pilot-scale centrifuge, the starch-based polymer was added before the synthetic polymer.

Figure 6 illustrates the used polymer dose, TS dewatered sludge, substitution, the separation ratio as well as the achieved TS of the dewatered sludge with respect to the reference synthetic polymer PK1440. The TS of the dewatered sludge achieved lay within an acceptable range from 23.2-25.7\%. The separation ratio of blends was lower compared to the reference PK1400 alone with a separation ratio of $90.2 \%$. For the latter trials with 50:50 the actual ratio of sludge TS differs slightly, because the dosing concentration of the H6864 was a little lower than the planned concentration of $0.2 \%$. According to the results, a

Table 4 | Operational parameters of sludge and centrifuge operation data at WWTP Steinhof

\begin{tabular}{|c|c|c|c|c|}
\hline \multicolumn{5}{|c|}{ Digested mixed sludge } \\
\hline TS & LOI & $\mathrm{pH}$ & Temperature & \\
\hline$\%$ & $\%$ of TS & & ${ }^{\circ} \mathrm{C}$ & \\
\hline $2.8-3.1$ & $70.2-72.4$ & $7.1-7.4$ & $32.5-36$ & \\
\hline \multicolumn{5}{|c|}{ Centrifuge operation data } \\
\hline Bowl speed & Rotational speed & Torque & Sludge throughput & Solid mass throughput \\
\hline rpm & $\mathrm{rpm}$ & $\%$ & $\mathrm{~m}^{3} /$ hour & $\mathrm{kg} / \mathrm{hour}$ \\
\hline$\sim 3,000$ & $1.3-3.0$ & $28-30$ & 20 & $566-614$ \\
\hline
\end{tabular}




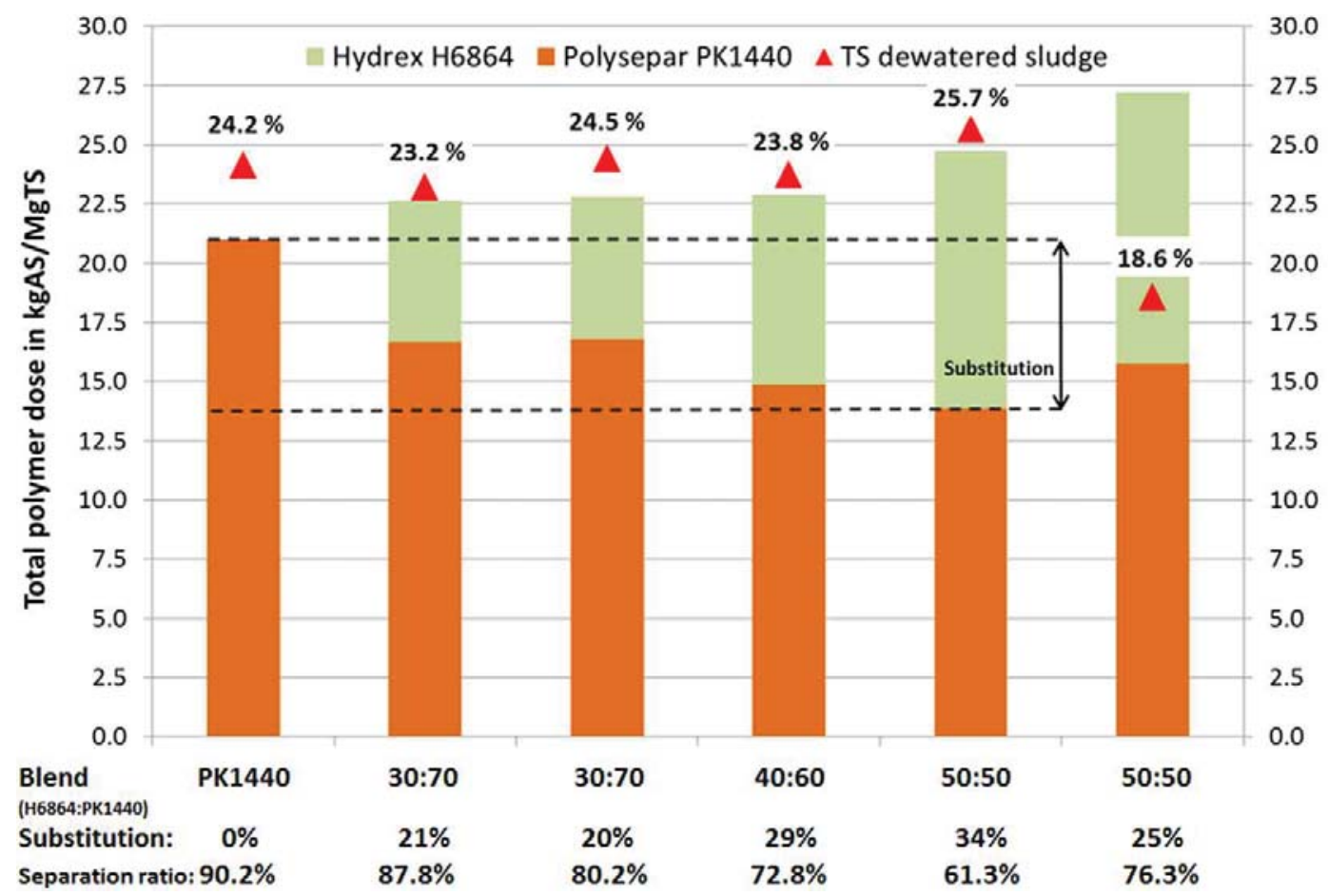

Figure 6 | Results of full-scale trials using digested mixed sludge at WWTP Steinhof.

substitution ratio of $34 \%$ can be achieved without decreasing the sludge TS.

In order to increase the separation ratio to an acceptable level, further trials optimizing the operational set-up are required. Torque and differential speed were adapted during the tests discussed. With regards to the experience gained with the pilot-scale centrifuge, these adjustments could improve the separation ratio.

\section{Full-scale trials at WWTP Schönebeck with drum filter}

Jar tests and drip-off tests were conducted to help with fullscale tests at WWTP Schönebeck. The promising results for blends of synthetic and starch-based polymers $\mathrm{H} 6864$ showed a substitution up to $67.5 \%$ of the synthetic polymer, although the shear stability still needs to be confirmed at full scale. Otherwise flocculation with the starch-based polymers H6864 alone did not show a sufficient flocculation for excess sludge at WWTP Schönebeck. To prove the sludge flocculation at full scale, one megagram blend consisting $50 \%$ of the starch-based polymer was first tested. After stable operation was achieved, samples were collected for detailed analysis. The result is given in Figure 7. The reference 1 and 2 with synthetic polymer K7CZST was measured before and after the blend test with the TS of thickened sludge being about 6\%. During the test using 50:50\% blend of H6864 and K7CZST, the sludge TS decreased to 3.7 and 3.8, which shows a lower stability of sludge flocs. Due to the low TS concentration of sludge, the H6864 fraction was reduced to one third (33:66\%) and tested in full sale again. The achieved TS of the thickened sludge for the blends with 33\% H6864 fraction were between $4.3 \%$ and $4.9 \%$, which was still below the reference value of $6 \%$. From operational aspects, the achieved TS values of between $4 \%$ and $5 \%$ were still in the acceptable range.

Full-scale tests were performed for the excess sludge with drum filter with blend of starch-based polymer and synthetic polymer. The formed flocs were shredded within the drum sieve due to insufficient shear stability. A maximal substitution of 31\% was possible with an acceptable sludge TS. Due to a low shear stress of belt filter press systems, this technology might be applicable. Further full-scale trials with belt thickener are planned at WWTP Putzhagen.

\section{Full-scale trials at WWTP Putzhagen (Guitersloh) with belt thickener}

The result of laboratory experiments is shown in Figure 3. The starch-based polymer H0661 showed a better 


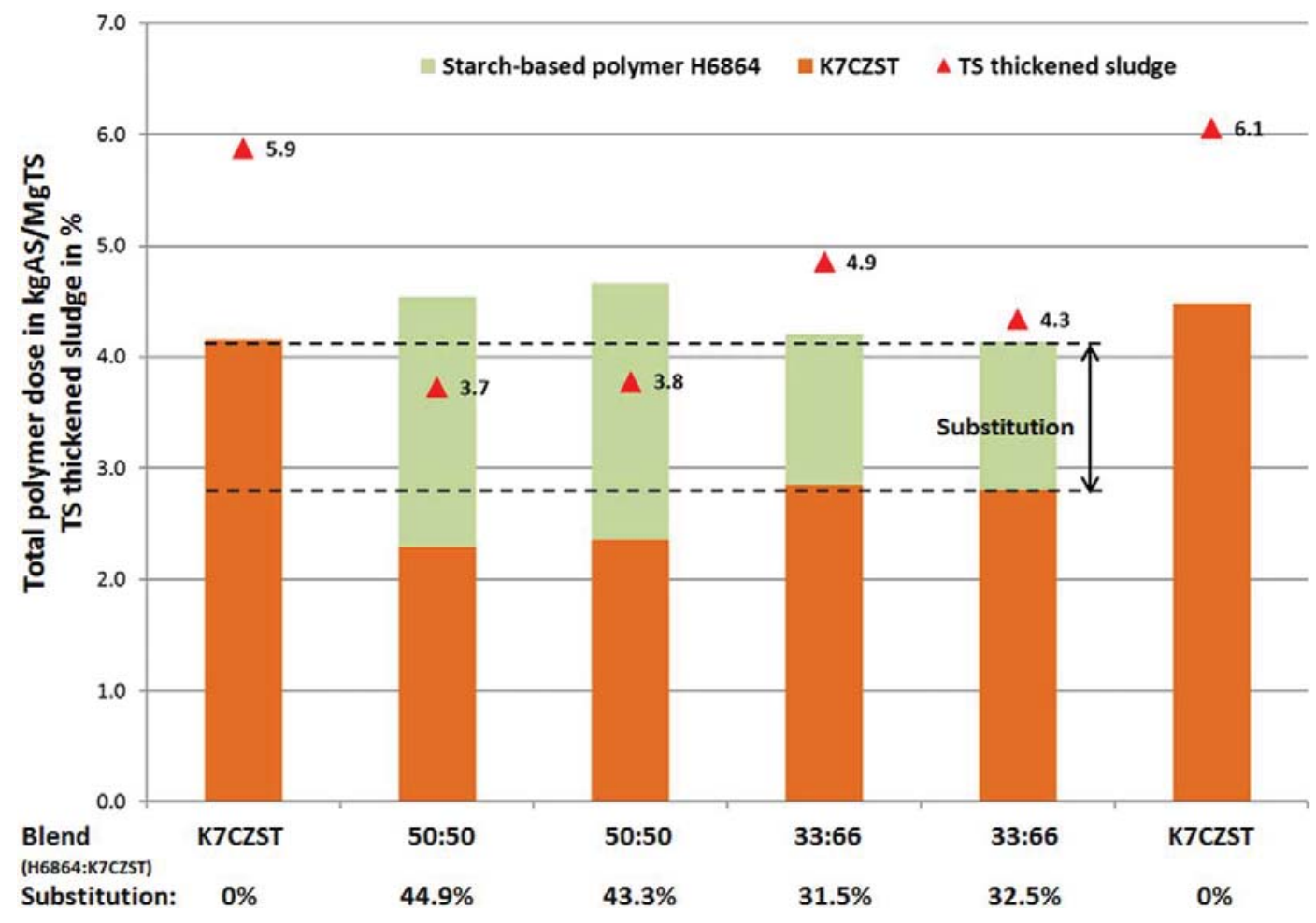

Figure 7 | Results of full-scale trials with excess sludge at WWTP Schönebeck.

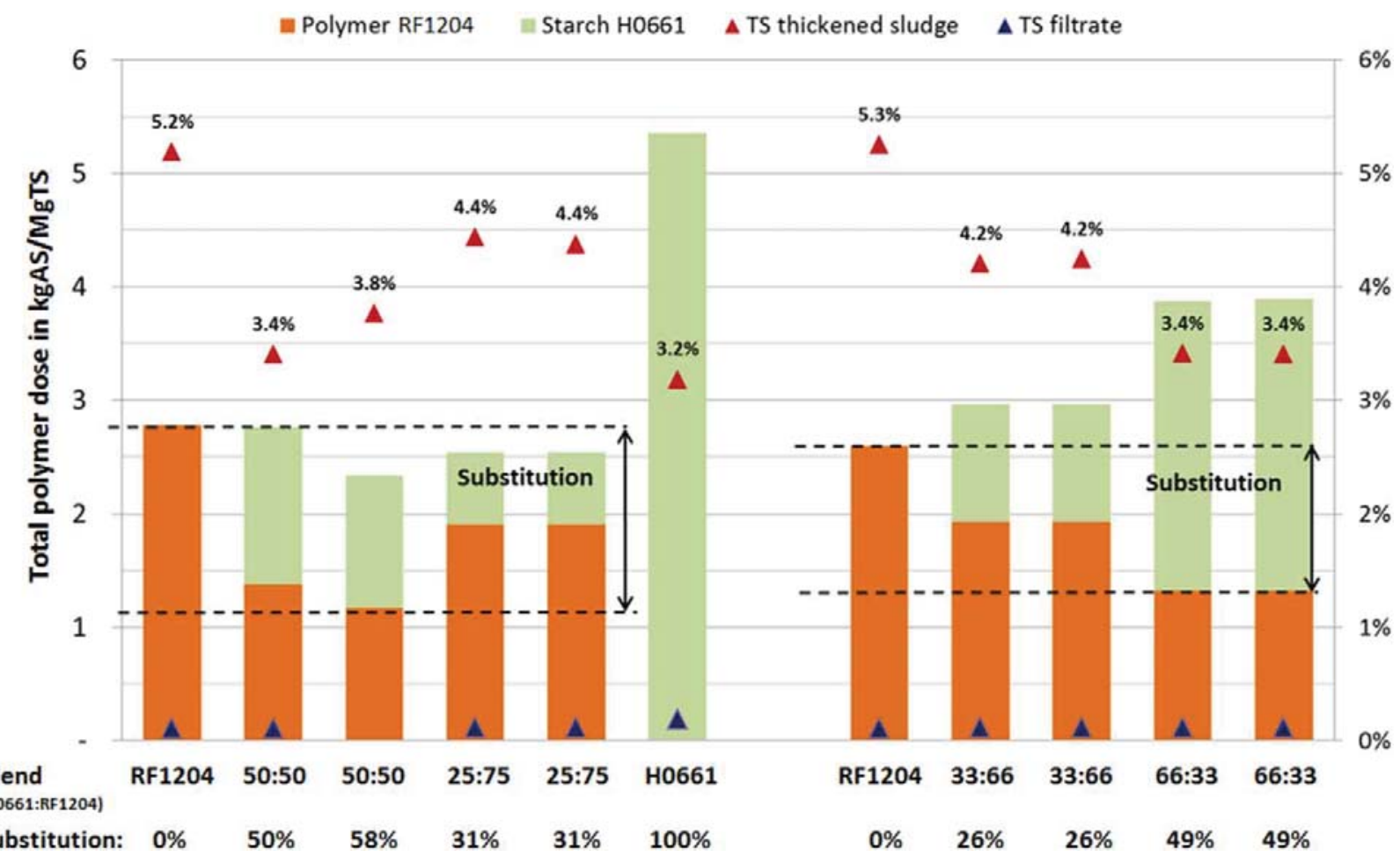

Figure 8 | Results of full-scale trials with excess sludge at WWTP Putzhagen. 
performance in the drip-off tests. In Figure 8, different blends of H0661 and RF1204 were tested: 25:75, 33:66, 50:50 and 66:33. According to the experience from the WWTP operator, achieving sludge TS with a ratio above $4 \%$ is a good result- for the belt thickener. As shown in Figure 8, 33\% substitution of polymer RF1204 is an acceptable quantity limit for operator. Substituting 50\% of the reference polymer RF1204 leads to an insufficient TS below 4\%. Thus, a blend of polymer and starch showed promising results for excess sludge thickening with a belt filter. The critical limit (max ratio) of starch is 33\%. With the experience of the WWTP operator, 25\% substitution with starch-based polymers would be a safe option.

The main objective of this study was to identify the starch-based eco-friendly polymer that demonstrates a similar performance for full-scale sludge dewatering to synthetic polymers. Based on the results of different sludge types and dewatering units, the following conclusions can be drawn:

- Non-digested excess sludge was more suitable for being treated with starch-based polymers, which with $70 \%$ substitution potential can be achieved.

- Substitution of 20\%-30\% of the PAM-based polymer was demonstrated achieving similar TS of the dewatered sludge with different dewatering devices.

- The starch-based polymer can meet the requirement of the German fertilizer ordinance for a decrease of $20 \%$ synthetic polymer.

- Optimization of operation parameters as well as machinery set up is recommended for achieving a high substitution potential.

\section{CONCLUSION}

In this paper, the approach of screening, laboratory-scale and pilot-scale trials paved the way for full-scale trials of starch-based polymers. The feasibility of applying a starchbased polymer in full-scale dewatering was shown. Based on the current selected starch-based polymer products, a partial substitution of 25-30\% synthetic polymer can be achieved. With further development of the product and optimization of the dewatering devices, in the foreseeable future, starch-based polymers have great potential as alternative flocculants to synthetic polymers.

\section{ACKNOWLEDGEMENTS}

At this point we would like to acknowledge all persons involved in the project P-REX and the WWTP operators and colleagues, who helped us to gain sufficient experience for the first trial applying a market-ready 'green polymer' in a full-scale centrifugation step. And special thanks to Christoph Siemers and Reinhardt Kratzel of SE|BS at WWTP Steinhof; Mike Dragon and Bernd Modler of OEWA at WWTP Schönebeck; Karl-Heinz Schröder and Maximilian Menke from the WWTP Putzhagen; Karsten Fülling of ISWW, TU Braunschweig. P-REX was financially supported by the European Commission (FP7 project P-REX, Grant agreement \#308645).

\section{REFERENCES}

BAFU 2013 Sludge Disposal in Switzerland. Swiss Federal Office for the Environment.

BMEL 2016 Second Regulation Amending the Fertilizer Regulation. Federal Ministry of Food and Agriculture (Germany).

Chiellini, E. \& Solaro, R. 1996 Biodegradable polymeric materials. Advanced Materials 8 (4), 305-313.

Destatis 2016 64\% of Sewage Sludge Incinerated in 2015. The Federal Statistical Office (Germany).

DüMV 2012 BGBl. I S. 2482, Regulation of Marketing of Fertilizers, Soil Additives, Crop Substrates, and Plant Additives (Düngemittelverordnung - DüMV). In.

DWA-M-366 2013 Mechanical Dewatering of Sewage Sludge. German Association for Water, Wastewater and Waste.

EurEau 2016 Sewage Sludge Situation and Trends 2016.

Eurostat 2016 Sewage Sludge Production and Disposal. In. 27.10.2016 edn, Statistical office of the European Union.

Khachan, M., Bader, R., Bhatia, S. \& Maurer, B. 2orI Comparative dewatering performance of slurries conditioned with synthetic polymers vs. eco-friendly polymers. In: $\mathrm{Geo}$ Frontiers 2011@sAdvances in Geotechnical Engineering (Jie Han \& Daniel E. Alzamora, eds). ASCE, Dallas, USA, pp. 3050-3058.

Lu, D., Xiao, C. \& Xu, S. 2009 Starch-based completely biodegradable polymer materials. Express Polymer Letters 3 (6), 366-375.

Pareta, R. \& Edirisinghe, M. J. 2006 A novel method for the preparation of starch films and coatings. Carbohydrate Polymers 63 (3), 425-431.

Scott, G. 2000 'Green' polymers. Polymer Degradation and Stability 68 (1), 1-7. 